\title{
Typical and atypical benign paroxysmal positional vertigo: Literature review and new theoretical considerations
}

\author{
Béla Büki ${ }^{\mathrm{a}}$, Marco Mandalà ${ }^{\mathrm{b}, *}$ and Daniele Nuti ${ }^{\mathrm{b}}$ \\ ${ }^{a}$ Department of Otolaryngology, Karl Landsteiner University Hospital Krems, Krems an der Donau, Austria \\ ${ }^{\mathrm{b}}$ Otology and Skull Base Surgery Department, Azienda Ospedaliera Universitaria Senese, Siena, Italy
}

Received 1 February 2014

Accepted 5 August 2014

\begin{abstract}
Atypical variants of benign paroxysmal positional vertigo (BPPV) are often encountered and frequently confusing. The authors present a hypothetical framework that accounts for all classical patterns of BPPV and several unusual variants such as BPPV without nystagmus, BPPV with downbeat nystagmus and BPPV with paradoxically direction-changing nystagmus. The authors introduce new concepts, such as "ipsicanal switch" and "horizontal short arm canalolithiasis" and suggest that their use may improve diagnosis and treatment in everyday clinical practice. The possible consequences of saccular otoconia detachment are reviewed according to the literature.
\end{abstract}

Keywords: Type 2 BPPV, canalolithiasis, cupulolithiasis, ipsicanal switch

\section{Introduction}

Benign paroxysmal positional vertigo (BPPV) is the most frequent single cause of isolated vertigo. According to the accepted theory, it is elicited when the mass load of the inner ear linear accelerometer (utricular otoconial debris) escapes and becomes mixed up with the mass load of the angular accelerometer (endolymph and cupulae of the semicircular canals), thereby sensitizing them to linear acceleration (gravity) and generating false information on angular acceleration. Currently, the diagnostic criteria of benign paroxysmal positional vertigo (BPPV) consist of vertical-torsional positional nystagmus evoked by the Dix-Hallpike maneuver (vertical canals involved) or a predominantly horizontal positional nystagmus after rolling the head sideways from the supine posi-

\footnotetext{
*Corresponding author: Marco Mandalà, Policlinico "Le Scotte", V.le Bracci, 16, Siena 53100, Italy. Tel.: +39 3480722748; E-mail: marcomand@hotmail.com.
}

tion (horizontal canals involved) (see Table 1) [4,15]. According to generally accepted theories, the peripheral vertical-torsional nystagmus in Dix-Hallpike position occurs typically due to canalo- or cupulolithiasis of the posterior canal, and in rare cases, of the anterior semicircular canal. Horizontal positional nystagmus, if peripheral, in lateral supine position may be elicited by the canalo- or cupulolithiasis of the horizontal canal. However, in the last decades, several atypical peripheral nystagmus patterns were described. These included no nystagmus at all in provoking positions and paradoxical, strong transient nystagmus patterns in different provoking positions. While peripheral BPPV without nystagmus has been a mysterious entity until recently, other patterns with changing nystagmus direction have been attributed to "canal switch", also called "canal conversion", when during head positioning, debris falls out of a canal and enters another one. During construction of explanations of different BPPV nystagmus patterns, all symptoms and signs (nystagmus) should be explained by possible movements of 
Table 1

Current criteria of diagnostic nystagmus in variants of BPPV (As provoked by positioning the patient to the Dix-Hallpike position from sitting (vertical canals affected) or in lateral supine position after rolling the head sideways when the patient is lying horizontally (horizontal canal affected))

\begin{tabular}{lll}
\hline & Cupulolithiasis & Canalolithiasis \\
\hline Horizontal canal & $\begin{array}{l}\text { Apogeotropic horizontal (beating laterally up in both lat- } \\
\text { eral supine positions) stronger on the contralateral side, } \\
\text { when the involved ear is uppermost; more prolonged, less } \\
\text { intense than in canalolithiasis) }\end{array}$ & $\begin{array}{l}\text { Geotropic horizontal (beating laterally down in both lat- } \\
\text { eral supine positions) stronger on the ipsilateral side, when } \\
\text { the involved ear is lowermost }\end{array}$ \\
Posterior canal & $\begin{array}{l}\text { Vertical torsional upbeat (geotropic), less intense, more } \\
\text { prolonged in respect to canalolithiasis }\end{array}$ & $\begin{array}{l}\text { Vertical-torsional upbeat (geotropic) nystagmus with a } \\
\text { short latency, provoked when the affected ear is lowermost } \\
\text { in the Dix-Hallpike position }\end{array}$ \\
& $?$ & $\begin{array}{l}\text { Provoked by both Dix-Hallpike and straight head hang- } \\
\text { ing positions, vertical-torsional, downbeat (apogeotropic), } \\
\text { should reverse its direction when sitting up }\end{array}$ \\
\hline
\end{tabular}

moving utricular otoconial debris in the three dimensional structure of the vestibular labyrinth. One should keep in mind that, when dislodged from the utricular macula, freely moving otoconia may move into any canal or be attached to any cupula of the ampullae, thereby causing canalolithiasis and/or cupulolithiasis of the individual canal (for a review see Parnes et al., 2003) [26]. Also, when theorizing about evoked nystagmus in BPPV variants it is first necessary to consider the position of the debris in the starting position, before examination, which is sitting (in case of vertical canal BPPV elicited by Dix-Hallpike position) or supine position before turning the head sideways (in case of horizontal canal BPPV). Then the movements of the debris and the cupulae should be reconstructed in the respective provocative positions. In our framework, debris should always be in the most inferior part of the compartment in the starting position; then, in the provocative position it sinks into the most inferior part of the compartment. Therefore, debris may be in the vestibulum, short arm, long arm of the canal and be attached to the cupulae.

In the present paper we summarize these theories and attempt to put forward a comprehensive framework of hypothetical causes for eye movements for all three semicircular canals (Table 2). These explanations should include universally accepted hypotheses (classical nystagmus types), BPPV cases without nystagmus and cases where canal-switch should explain changing and paradox nystagmus patterns.

\section{Examination methods}

When examining patients with BPPV, the examiner first should try to elicit typical positional nystagmus depending of the most predictable canal involved on the basis of symptomatology. For the vertical canals, the examination, the so-called Dix-Hallpike positioning should start in the sitting position by initially turning the patient's head in sitting by $45^{\circ}$ in the yaw plane toward the side to be examined and then pitching the patient backwards by $130^{\circ}$ from upright, to an eardown, head-hanging position, i.e., approx. $40^{\circ}$ below the earth-horizontal [2]. Since in the Dix-Hallpike position the patient's head is hanging upside down, an upbeat nystagmus with a fast component toward the center of the earth also beats towards the top of the head. To resolve this, it is called an 'upbeat-geotropic nystagmus'. Nystagmus beating down, in the direction of the chin, is called a 'positional downbeat nystagmus', but in a head-hanging position this is in fact 'apogeotropic'. The torsional component is named by the fast movement of the upper pole of the eyes.

For the lateral canals, the examiner should try to elicit positional nystagmus in the supine position carrying out head rolls to both lateral positions. First, the patient is lying on his/her back face upwards. From this position the head is slowly and gently turned 90 degrees into the lateral position (e.g. to the right) and the ensuing nystagmus is observed. Then the other side is examined.

\section{Classical nystagmus patterns}

\subsection{Posterior canal long arm canalolithiasis}

According to the universally accepted theory, movements of the debris away from the cupula causes a geotropic torsional upbeat nystagmus with a short latency, provoked when the affected ear is lowermost in the Dix-Hallpike position. When the patients sit up from the head hanging position, there should be a re- 
Table 2

Suggested criteria of diagnostic nystagmus in variants of BPPV (As provoked by positioning the patient to the Dix-Hallpike position from sitting (vertical canals affected) or in lateral supine position after rolling the head sideways when the patient is lying horizontally (horizontal canal affected))

\begin{tabular}{|c|c|c|c|}
\hline & $\begin{array}{l}\text { Short arm } \\
\text { canalolithiasis }\end{array}$ & Cupulolithiasis & Long arm canalolithiasis \\
\hline Horizontal canal & $\begin{array}{l}\text { Apogeotropic horizontal (beating } \\
\text { laterally up in lateral supine posi- } \\
\text { tion when the involved ear is lower- } \\
\text { most and no nystagmus in the con- } \\
\text { tralateral lateral position) }\end{array}$ & $\begin{array}{l}\text { Apogeotropic horizontal (beating } \\
\text { laterally up in both lateral supine } \\
\text { positions; stronger on the contralat- } \\
\text { eral side, when the involved ear is } \\
\text { uppermost). }\end{array}$ & $\begin{array}{l}\text { Geotropic horizontal (beating laterally down } \\
\text { in both lateral supine positions) stronger on the } \\
\text { ipsilateral side, when the involved ear is low- } \\
\text { ermost. } \\
\text { Peri-cupulo canalolithiasis can cause an apo- } \\
\text { geotropic horizontal nystagmus (beating lat- } \\
\text { erally up in both lateral supine positions; } \\
\text { stronger on the contralateral side, when the in- } \\
\text { volved ear is uppermost). }\end{array}$ \\
\hline Posterior canal & $\begin{array}{l}\text { No nystagmus in Dix-Hallpike po- } \\
\text { sition but sitting up vertigo either in } \\
\text { the RALP or LARP plane }\end{array}$ & $\begin{array}{l}\text { Depending on anatomy: either no } \\
\text { nystagmus in Dix-Hallpike posi- } \\
\text { tion, or apogeotropic downbeat }\end{array}$ & $\begin{array}{l}\text { Geotropic-torsional upbeat nystagmus with a } \\
\text { short latency, provoked when the affected ear } \\
\text { is lowermost in the Dix-Hallpike position }\end{array}$ \\
\hline Anterior canal & $\begin{array}{l}\text { Sometimes acutely caused by the } \\
\text { Dix-Hallpike manoeuver: } \\
\text { apogeotropic downbeat }\end{array}$ & $\begin{array}{l}\text { Same as anterior short arm and long } \\
\text { arm canalolithiasis, more persistent } \\
\text { repeatable }\end{array}$ & $\begin{array}{l}\text { Apogeotropic downbeat nystagmus with a } \\
\text { small torsional fast-phase, which beats toward } \\
\text { the affected ear (affected ear uppermost in } \\
\text { Dix-Hallpike position) } \\
\text { (Occurs possibly rarely because the position of } \\
\text { the canal) }\end{array}$ \\
\hline
\end{tabular}

versal of the nystagmus, and a downbeat nystagmus ensues, because the debris reverse the direction of their movement $[2,4,15]$.

\subsection{Posterior canal cupulolithiasis}

Until now, posterior cupulolithiasis has been postulated to cause a nystagmus similar to canalolithiasis, only more persistent $[2,16,26]$. As we shall see below, we provide an alternative hypothesis.

\subsection{Horizontal canal canalolithiasis}

The nystagmus is geotropic horizontal (beating laterally down in both lateral supine positions) stronger on the ipsilateral side, when the involved ear is lowermost [22]. Despite, this is the leading hypothesis, in our opinion; canalolithiasis of the horizontal canal could also provoke an apogeotropic nystagmus due to a different initial position of the particles in the canal, much closer to the ampulla (peri-cupula form). Otoconia move in the opposite direction with respect to the geotropic form. In this variant, the nystagmus is apogeotropic horizontal (beating laterally up in both lateral supine positions) stronger on the contralateral side, when the involved ear is uppermost. This idea is corroborated by the fact that it is possible to transform apogeotropic into geotropic nystagmus by using slow, gentle maneuvers such as turning the head sideways, which would not be effective if the otoconia were attached to the cupula. It is even possible to change the apogeotropic into the geotropic nystagmus simply by maintaining the patient in a prolonged lateral position on the affected side. In the event that the affected side has been incorrectly identified, the forced prolonged position causes the geotropic nystagmus to become apogeotropic, and this is again incompatible with the cupulolithiasis theory. So if otoconial debris are located in the anterior part of the horizontal canal, rotation of the head to the affected side causes the fall of debris away from the ampulla, causing an inhibitory nystagmus that beats toward the healthy, uppermost ear. Rolling onto the opposite side causes debris to return toward the ampulla, triggering a more intense nystagmus, again apogeotropic, beating toward the affected, uppermost ear [20]. It can be speculated if this variant could arise from detached otoconia from cupulolithiasis.

\subsection{Horizontal canal cupulolithiasis}

The nystagmus is apogeotropic horizontal (beating laterally up in both lateral supine positions) stronger on the contralateral side, when the involved ear is uppermost [14,25]. Apogeotropic positional nystagmus due to cupulolithiasis of the horizontal canal should be less intense and more prolonged [13]. 


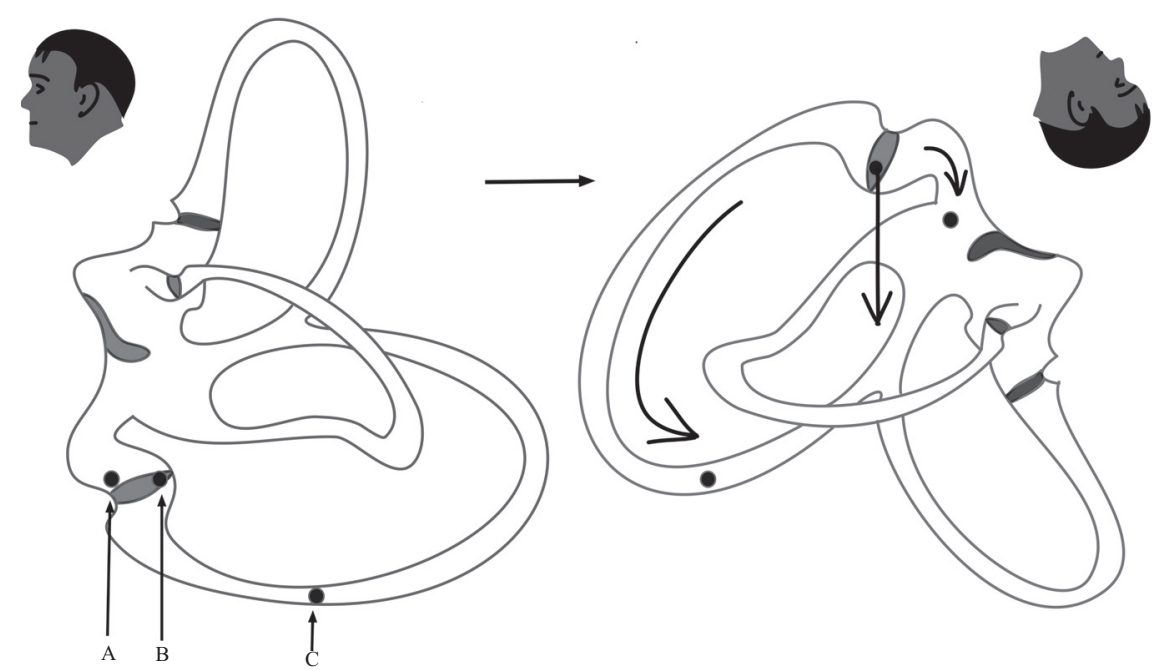

Fig. 1. Posterior canal involvement in sitting (left) and Dix-Hallpike position (right). Left panel panel: $\mathrm{A}=$ debris in the short arm; $\mathrm{B}=$ cupulolithiasis, $\mathrm{C}=$ debris in the long arm; Right panel: arrows show hypothetical movements of debris or in the case of cupulothiasis the direction of the gravity vector.

\subsection{Anterior canal canalolithiasis and cupulolithiasis}

This may occur rarely (see the Chapter written by Nuti and Zee in [8]), still, it is possible that during the night, debris in the common crus moves toward the ampulla in the long arm during a turn during sleep in supine position. Hypothetically, there is another possibility of generation mechanism: when acutely dislocated, the debris falls onto the cupula immediately during (and because of) the Dix-Hallpike positioning, the short arm/opening of the anterior ampulla being immediately below the utricular macula in the DixHallpike position [6]. In anterior cupulolithiasis, in Dix-Hallpike position an apogeotropic downbeat nystagmus is elicited, with a small torsional fast-phase, which beats toward the affected ear (affected ear uppermost in Dix-Hallpike position) [2]. As Bertholon et al. [3] and Aw et al. [2] stated, anterior SCC BPN could be provoked by the Dix-Hallpike test to either side, because the anterior SCC ampulla is above the posterior SCC ampulla. According to these authors, as in anterior SCC involvement the small torsional fast-phase may beat towards the involved ear with the affected ear uppermost or lowermost in the Dix-Hallpike position, observation of the direction of the torsional component, rather than the side of the Dix-Hallpike test, lateralizes the affected side: the torsional fast-phase of the BPN will beat toward the affected ear [2]. If there is a cupulolithiasis, then the debris attaches to the cupula and the nystagmus may be more repeat- able, but the elicited nystagmus should be identical with the downbeat-torsional nystagmus caused by anterior canalolithiasis (Fig. 2). Theoretically, one single Dix-Hallpike maneuver should solve the anterior canalolithiasis, because the debris should travel in the long arm and fall out through the common crus into the utricle.

\section{Atypical nystagmus arising in the vertical canals}

\subsection{BPPV without nystagmus and positional downbeat nystagmus from the posterior canal}

The above, widely accepted diagnostic criteria are valid for the overt BPPV, which is going with nystagmus and fairly intensive acute vertigo for 20-30 seconds immediately after positioning. However, apparently there is another, more latent, more chronic variant, when patients have typical BPPV symptoms (short vertigo when bending forward, lying down, sitting up or turning over in bed) but no nystagmus is evoked by Dix-Hallpike and supine roll maneuvers. Until now, this was called "subjective BPPV" and it has not been characterized. In an attempt to explain this, Büki et al. coined the term "type 2 BPPV" [9]. After "short arm" canalolithiasis had been already suggested by Oas back in 2001 [24], this variant was also hypothetically contributed to freely moving debris in the short arm of posterior canal. As a diagnostic criterion, the unilat- 
eral sitting-up vertigo/body sway was suggested. This is felt/shown by the patients during sitting up from the Dix-Hallpike position, on one side, but not from the other.

Another atypical variant was suggested by Cambi et al. [11], who described peripheral positional downbeat nystagmus, possibly of posterior canal origin. This was a new theory, since until recently, peripheral positional downbeat nystagmus was traditionally linked to the anterior canals. Vannucchi et al. [31], who also noted atypical downbeat nystagmus suggested that downbeat nystagmus could arise from the posterior canal. Their hypothesis involved debris being in the highest part of the posterior canal at the beginning and starting backward in the long arm during the Dix-Hallpike position [31]. This theory could not explain the missing reversal of the downbeat nystagmus, which is a quite common feature of this downbeat nystagmus of posterior canal origin.

Büki (Otol Neurotol in press) tried to synthetize the above new findings. According to this, it is hypothetically possible that otoconia become dislocated but do not fall into the common crus of the vertical canals or into the horizontal canal; in these cases they may gravitate toward the most posterior part of the utriculus, the ampulla of the posterior canal. Then, depending on their behavior (freely moving or sticking to the cupula) and the precise position of the posterior ampulla (which varies [6]), either no nystagmus or a slow downbeat nystagmus should ensue when the patient is positioned from sitting to a Dix-Hallpike position. According to the author, such scenarios could hypothetically explain commonly seen clinical entities such as "subjective BPPV" and/or cases with a peripheral positional downbeat nystagmus. Should these theories be accepted (to prove or disprove them will be difficult), it would be possible to add the following two varieties to the existing classical ones:

\subsection{Posterior canal cupulolithiasis}

Debris attached to the cupula deflects it. Depending on anatomy: either no nystagmus in Dix-Hallpike position, or apogeotropic downbeat nystagmus arises in Dix-Hallpike position, to be elicited by bilateral DixHallpike maneuver (may be stronger when affected ear lowermost). Torsional component, if any, beats toward the contralateral ear.

\subsection{Posterior canal short arm canalolithiasis}

Because debris is moving out from the short arm, no nystagmus is elicited in Dix-Hallpike position but sitting up vertigo/body sway either in the diagonal vertical planes corresponding right anterior- left posterior or left anterior right posterior semicircular canals. Both in posterior canal cupulolithiasis and posterior short arm canalolithiasis a strong vegetative reaction (nausea, sweating) has been noted after repeated positioning which is out of proportion considering the missing nystagmus [9].

\section{Atypical nystagmus arising in the horizontal canals}

\subsection{Horizontal canal short arm canalolithiasis}

Hypothetically, when debris falls into the short arm of the horizontal canal, it falls directly onto the cupula, causing an apogeotropic horizontal nystagmus (beating laterally up in lateral supine position when the involved ear is lowermost). During supine roll in the contralateral direction it may fall out, therefore no nystagmus is to be anticipated in the contralateral supine position. Although we frequently encounter this version after Epley/Semont maneuvers, we are not aware of any previous paper suggesting this mechanism involving the short arm. Other authors also described this nystagmus pattern but explained it by an atypical starting position of the debris in the long arm of the horizontal canal [10] as originally suggested by Vannucchi and Pecci [30].

\section{Atypical nystagmus with a canal switch}

\subsection{Posterior-horizontal canal switch}

Canal switch due Epley/Semont maneuvers is a well-known phenomenon. In these cases debris from one canal moves into another, thereby successively producing the typical nystagmus first of the canal-oforigin, then of the secondary canal. The most usual pattern is the posterior canalolithiasis-to-horizontal canalolithiasis. The debris in these cases seems to be big enough not to be dissolved during the travel along one canal, out of it, and into the other. We remind here, that labyrinthine otoconia maintenance and calcium deposition is a tightly regulated process [21], which 


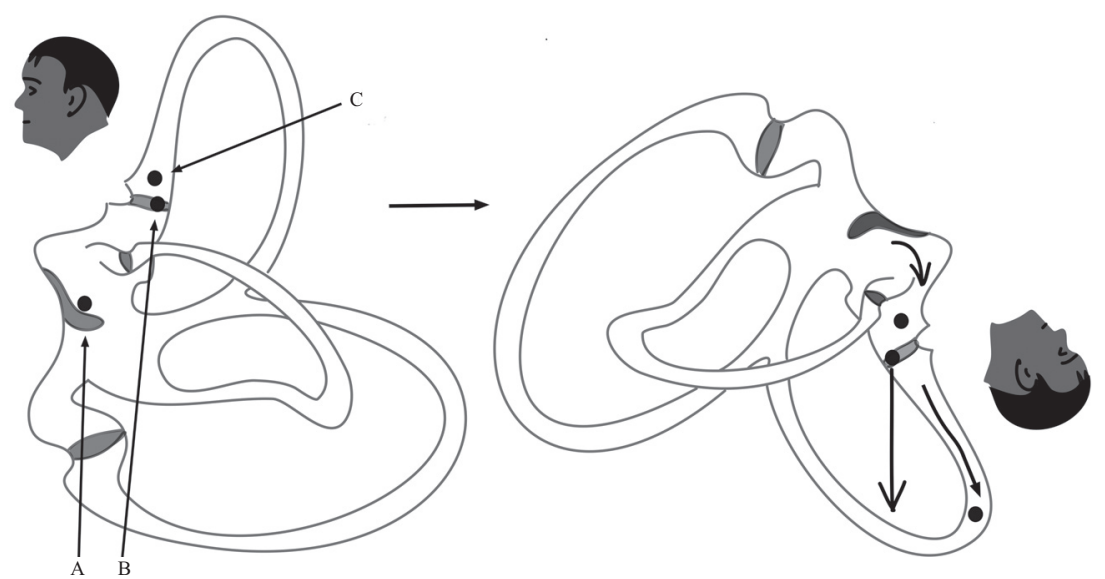

Fig. 2. Anterior canal involvement in sitting (left) and Dix-Hallpike position (right). Left panel: $\mathrm{A}=$ debris on the utricular macula; $\mathrm{B}=$ cupulolithiasis, $\mathrm{C}=$ debris in the long arm; Right panel: arrows show hypothetical movements of debris or in the case of cupulothiasis the direction of the gravity vector.

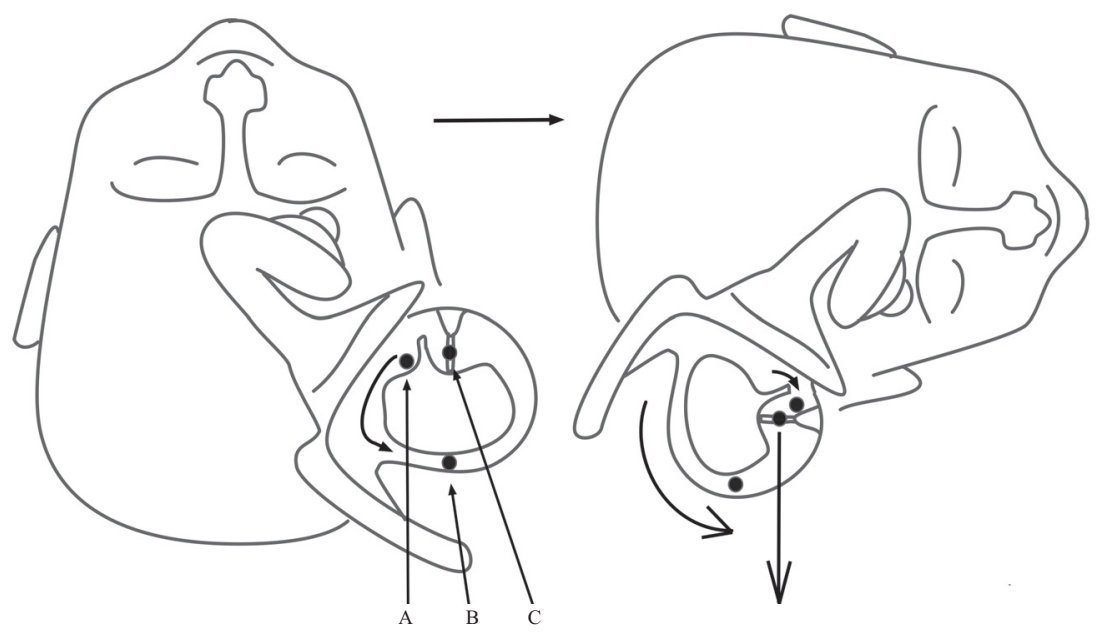

Fig. 3. Horizontal canal involvement in supine (left) and in the right lateral position (right). Left panel panel: $\mathrm{A}=$ debris in the short arm; $\mathrm{B}=$ debris in the long arm; $\mathrm{C}=$ cupulolithiasis. Arrow shows the hypothetical movements of the debris during ipsicanal switch; Right panel: arrows show hypothetical movements of debris or in the case of cupulothiasis the direction of the gravity vector.

requires active mechanisms, because the utricular calcium concentration is low $(200 \mu \mathrm{mol} / \mathrm{L})$. Also, freely moving otoconia should be dissolved after a time [34]. In some cases, however, a persistent otolithic debris can be observed for a longer time [33]. As a result of age-related degeneration, otoconia may escape the macula, and subsequently dissolve [3], except possibly, when they are confined to a small space with pathologically high calcium concentration.

\subsection{Horizontal ipsicanal switch}

Short arm canalolithiasis in the horizontal canal could hypothetically switch into a horizontal long arm canalolithiasis, if the debris falls out of the short arm during a supine roll in the contralateral direction and it moves through the vestibulum, into the ipsilateral long arm (Fig. 3) (or, in other cases, reverse, from the long arm into the short). This causes a reversal of the nystagmus direction when the patient turns his or her head into repeated lateral supine position with the affected ear lowermost. Earlier Nuti et al. suggested another theory for this atypical nystagmus [23], involving debris, which is initially positioned in an atypical location. Earlier authors explained this by a conversion of canalolithiasis into cupulolithiasis [17,29]. Again, the horizontal ipsicanal switch is being suggested for the first time in the present paper. 


\subsection{Atypical nystagmus during atypical positioning}

For the sake of completeness we list here two frequent manifestations, which may give diagnostic clues. First, the lying-down nystagmus, which arises when patients are sitting bending forward and, for the sake of investigation, elevate their head or lie down into supine position. In this case, debris in the horizontal canal, which is initially in an anterior position close to the ampulla (or attached to the cupula of the horizontal canal), sink down causing a horizontal nystagmus, which may be confused with a spontaneous nystagmus.

Second, if lying patients with acute posterior canalolithiasis are made to sit up, this may elicit a transient (sometimes rather long lasting) positional downbeat nystagmus (the opposite of the geotropic-upbeat nystagmus in the Dix-Hallpike position), which may also cause some confusion.

\section{Frequency of variants}

First of all, it has been suggested, that the right labyrinth is preferentially affected [32] with canalolithiasis. It has not been specified if this observation should only be valid for canalolithiasis or for cupulolithiasis as well. Of course, this preferential affection remains to be verified in a new epidemiological study in which the new criteria (no nystagmus provoked in DixHallpike position in hypothetical posterior cupulolithiasis etc.) are applied, should they be accepted by the scientific community. But then, this is true concerning all kinds of epidemiologic studies: should the new hypothetical mechanisms be generalized, new epidemiological studies should be carried out. A good example for this is for instance vestibular migraine or phobic vertigo, which may overlap with BPPV without nystagmus.

Another example is the paper of Jeong et al. [18], who recruited 100 consecutive patients with a diagnosis of idiopathic BPPV for a study and excluded eightyfour patients who reported a typical history suggestive of BPPV without positional nystagmus. Did these patients with "subjective" BPPV, in fact, have BPPV or not? If yes, the percentage of "subjective BPPV" caused perhaps posterior short arm canalolithiasis or posterior cupulolithiasis was $40 \%$ (!) in this study.

Concerning an unilateral end organ there is also a preferential involvement: the upper part of the vestibulum, the anterior canal and ampulla seem to be involved practically not at all or at least less frequently than the lower parts, the posterior canal or ampulla, where debris may be trapped or is deposited, respectively. The classical BPPV, when the debris has to hit the orifices of the long arms may be in the reality not as frequent, as vestibulolithiasis, when debris does't have to find the openings, just sink into the most posterior parts (which is posterior short arm) and move there to and fro. What may make the classical variety more frequent is, that in upright position the utricular macula is almost horizontal and disattachment is not favoured but when it comes to disattachment (because the uticular surface becomes vertically positioned or upside down, in supine position), the orifices are below the utricular macula.

\section{Differential symptomatology}

Posterior canalolithiasis should occur mainly in supine position, when the common crus is positioned below the utricular macula. Then, during the night debris may move into the vertical canals and the first symptoms arise when sitting up in the morning or turning over in bed. During sitting up, the debris may fall out of the anterior canal spontaneously and be trapped in the posterior one for a longer time. Then the Epley/Semont maneuvers should help.

In contrast, vertigo/dizziness due to horizontal canalolithiasis or posterior short arm canalolithiasis may start also during the day, in upright position, after slight horizontal/rolling head movements. Such a history of complaints may be confused with seemingly spontaneous attacks.

\section{Differential diagnosis}

It is important to stress, that positional downbeat nystagmus may be caused by a number of central etiologies, including posterior fossa tumor, cerebellar or spinocerebellar degeneration, multiple sclerosis, Arnold-Chiari malformation, lithium toxicity, or paraneoplastic diseases. It can only be considered 'peripheral' when all these pathologies have been reliably excluded [2]. This is markedly true in BPPV without nystagmus. Only perhaps in the case of typical symptoms and transient geotropic nystagmus upon Dix-Hallpike provocation that then cannot be elicited after an Epley/Semont maneuver (such as with posterior canalolithiasis), the examiner may be confident about a peripheral cause. Apart from central patholo- 
gies, differential diagnosis of BPPV should include migraine [1], phobic postural vertigo [7], and chronic subjective dizziness [28], the latter 2 groups being anxiety-related.

\section{Saccular otoconia degeneration: No vertigo but possibly hearing loss}

Current models of BPPV incorporate only utricular otoconia, because the utriculus and the SCC ampullae share the same fluid compartment, in contrast to the sacculus, which is only connected to the utricle by a thin channel, the utriculo-saccular duct. However, using scanning electron microscopy, it has been shown that surface pitting, hollowing out, fragmentation, and dislodgement of saccular otoconia starts earlier that utricular otoconia degeneration [27]. The saccule is connected to the cochlear endolymphatic duct through the ductus reuniens and calcium concentration in the cochlear endolymph is very low $(20 \mu \mathrm{M}$ [5]). Pathological elevation of calcium concentration should inhibit mechanoelectrical transduction in the cochlear hair cell stereocilia. This is why the pathogenetic role of dislodged saccular otoconia in acute or chronic hearing loss has been suggested. Otoconial debris, with tissue reaction, was demonstrated within the ductus reuniens and cochlear duct, as far distal as the middle of the ascending basal limb [12] and the blockage of ductus reuniens has been hypothetically implicated in the generation of cochlear hydrops [20]. Back in 1971 Johnsson [19] suggested that saccule degeneration should be considered an integral part of the presbyacusis syndrome. Although the syndrome "cochleosaccular degeneration" had been a familiar term in the nineteensixties and seventies, it has been largely forgotten by now. Perhaps by reconsidering this hypothetical framework and examining it with modern methods, it will be possible to explain several features of acute/chronic hearing loss and tinnitus.

\section{Conclusions}

BPPV is a frequent entity. In the light of the arguments presented above it may be even more frequent then we might think today. The above-presented hypotheses are not directly provable but then this has been the case in the past with the various varieties of BPPV. Should these theories some time in the future be accepted, BPPV cases without nystagmus or with atypical nystagmus patterns would cease to be puzzling clinicians in the everyday practice. With this paper, the authors would like to stimulate discussion and perhaps further studies concerning this entity, which may cause so much distress for the patients and which can be cured so easily, if diagnosed.

\section{Acknowledgments}

The authors thank Prof. David Zee for critically revising the manuscript and writing the abstract. We also thank two anonymous reviewers for their dedicated work and useful suggestions.

\section{Conflict of interest}

The authors report no conflict of interest.

\section{References}

[1] K. Agarwal, A.M. Bronstein, M.E. Faldon, M. Mandala, K. Murray and Y. Silove, Visual dependence and BPPV, J Neurol 259 (2012), 1117-1124.

[2] S.T. Aw, M.J. Todd, G.E. Aw, L.A. McGarvie and G.M. Halmagyi, Benign positional nystagmus: A study of its threedimensional spatio-temporal characteristics, Neurology 64 (2005), 1897-1905.

[3] P. Bertholon, A.M. Bronstein, R.A. Davies, P. Rudge and K.V. Thilo, Positional down beating nystagmus in 50 patients: cerebellar disorders and possible anterior semicircular canalithiasis, J Neurol Neurosurg Psychiatry 72 (2002), 366-372.

[4] N. Bhattacharyya, R.F. Baugh, L. Orvidas, D. Barrs, L.J. Bronston, S. Cass, A.A. Chalian, A.L. Desmond, J.M. Earll, T.D. Fife, D.C. Fuller, J.O. Judge, N.R. Mann, R.M. Rosenfeld, L.T. Schuring, R.W. Steiner, S.L. Whitney, J. Haidari, O.-H. American Academy of and F. Neck Surgery, Clinical practice guideline: benign paroxysmal positional vertigo, Otolaryngol Head Neck Surg 139 (2008), S47-81.

[5] S.K. Bosher and R.L. Warren, Very low calcium content of cochlear endolymph, an extracellular fluid, Nature $\mathbf{2 7 3}$ (1978), 377-378.

[6] A.P. Bradshaw, I.S. Curthoys, M.J. Todd, J.S. Magnussen, D.S. Taubman, S.T. Aw and G.M. Halmagyi, A mathematical model of human semicircular canal geometry: A new basis for interpreting vestibular physiology, J Assoc Res Otolaryngol 11 (2010), 145-159.

[7] T. Brandt, D. Huppert and M. Dieterich, Phobic postural vertigo: A first follow-up, J Neurol 241 (1994), 191-195.

[8] A.M. Bronstein, Oxford textbook of vertigo and imbalance, Oxford University Press, Oxford, U.K., 2013.

[9] B. Buki, L. Simon, S. Garab, Y.W. Lundberg, H. Junger and D. Straumann, Sitting-up vertigo and trunk retropulsion in patients with benign positional vertigo but without positional nystagmus, J Neurol Neurosurg Psychiatry 82 (2011), 98104. 
[10] L. Califano, A. Vassallo, M.G. Melillo, S. Mazzone and F. Salafia, Direction-fixed paroxysmal nystagmus lateral canal benign paroxysmal positioning vertigo (BPPV): Another form of lateral canalolithiasis, Acta Otorhinolaryngol Ital 33 (2013), 254-260.

[11] J. Cambi, S. Astore, M. Mandala, F. Trabalzini and D. Nuti, Natural course of positional down-beating nystagmus of peripheral origin, J Neurol 260 (2013), 1489-1496.

[12] R. Gussen, Saccule otoconia displacement into cochlea in cochleosaccular degeneration, Arch Otolaryngol 106 (1980), 161-166.

[13] T.C. Hain, T.M. Squires and H.A. Stone, Clinical implications of a mathematical model of benign paroxysmal positional vertigo, Ann N Y Acad Sci 1039 (2005), 384-394.

[14] S.F. Hall, R.R. Ruby and J.A. McClure, The mechanics of benign paroxysmal vertigo, J Otolaryngol 8 (1979), 151-158.

[15] J. Hornibrook, Benign Paroxysmal Positional Vertigo (BPPV): History, Pathophysiology, Office Treatment and Future Directions, Int J Otolaryngol 2011 (2011), 835671.

[16] H. Ichijo, Cupulolithiasis of the posterior semicircular canal, Am J Otolaryngol 34 (2013), 458-463.

[17] T. Imai, N. Takeda, G. Sato, K. Sekine, M. Ito, K. Nakamae and T. Kubo, Changes in slow phase eye velocity and time constant of positional nystagmus at transform from cupulolithiasis to canalolithiasis, Acta Otolaryngol 128 (2008), 22-28.

[18] S.H. Jeong, J.S. Kim, J.W. Shin, S. Kim, H. Lee, A.Y. Lee, J.M. Kim, H. Jo, J. Song and Y. Ghim, Decreased serum vitamin D in idiopathic benign paroxysmal positional vertigo, $J$ Neurol 260 (2013), 832-838.

[19] L.G. Johnsson, Degenerative changes and anomalies of the vestibular system in man, Laryngoscope 81 (1971), 16821694.

[20] R.S. Kimura, H.F. Schuknecht, C.Y. Ota and D.D. Jones, Obliteration of the ductus reuniens, Acta Otolaryngol 89 (1980), 295-309.

[21] Y.W. Lundberg, X. Zhao and E.N. Yamoah, Assembly of the otoconia complex to the macular sensory epithelium of the vestibule, Brain Res 1091 (2006), 47-57.

[22] J.A. McClure, Horizontal canal BPV, J Otolaryngol 14 (1985), 30-35.
[23] D. Nuti, P. Vannucchi and P. Pagnini, Benign paroxysmal positional vertigo of the horizontal canal: A form of canalolithiasis with variable clinical features, J Vestib Res 6 (1996), 173184.

[24] J.G. Oas, Benign paroxysmal positional vertigo: A clinician's perspective, Ann N Y Acad Sci 942 (2001), 201-209.

[25] P. Pagnini, D. Nuti and P. Vannucchi, Benign paroxysmal vertigo of the horizontal canal, ORL J Otorhinolaryngol Relat Spec 51 (1989), 161-170.

[26] L.S. Parnes, S.K. Agrawal and J. Atlas, Diagnosis and management of benign paroxysmal positional vertigo (BPPV), CMAJ 169 (2003), 681-693.

[27] M.D. Ross, D. Peacor, L.G. Johnsson and L.F. Allard, Observations on normal and degenerating human otoconia, Ann Otol Rhinol Laryngol 85 (1976), 310-326.

[28] J.P. Staab, Chronic subjective dizziness, Continuum (Minneap Minn) 18 (2012), 1118-1141.

[29] S. Steddin, D. Ing and T. Brandt, Horizontal canal benign paroxysmal positioning vertigo (h-BPPV): Transition of canalolithiasis to cupulolithiasis, Ann Neurol 40 (1996), 918922.

[30] P. Vannucchi and R. Pecci, About nystagmus transformation in a case of apogeotropic lateral semicircular canal benign paroxysmal positional vertigo, Int J Otolaryngol 2011 (2011), 687921.

[31] P. Vannucchi, R. Pecci and B. Giannoni, Posterior semicircular canal benign paroxysmal positional vertigo presenting with torsional downbeating nystagmus: An apogeotropic variant, Int J Otolaryngol 2012 (2012), 413603.

[32] M. von Brevern, T. Seelig, H. Neuhauser and T. Lempert, Benign paroxysmal positional vertigo predominantly affects the right labyrinth, J Neurol Neurosurg Psychiatry 75 (2004), 1487-1488.

[33] C.G. Wright, R.C. Rouse, G.H. Zajic, S.D. Schaefer, D.G. Hubbard and L.A. Barnard, A calcareous concretion in the posterior semicircular duct of a human labyrinth, Am J Otolaryngol 3 (1982), 196-201.

[34] G. Zucca, S. Valli, P. Valli, P. Perin and E. Mira, Why do benign paroxysmal positional vertigo episodes recover spontaneously? J Vestib Res 8 (1998), 325-329. 